\title{
Adhesion and colonisation of Candida krusei on host surfaces
}

\author{
Y. H. SAMARANAYAKE, P. C. WU, L. P. SAMARANAYAKE*, M. SO and K. Y. YUEN $\dagger$ \\ Department of Pathology (Oral), University of Hong Kong, * Oral Biology Unit, Faculty of Dentistry, University of \\ Hong Kong, 34 Hospital Road and $\dagger$ Department of Microbiology, Faculty of Medicine, University of Hong Kong, \\ Queen Mary Hospital, Pokfulam Road, Hong Kong
}

\begin{abstract}
Summary. Candida krusei is an emerging pathogen, especially in immunocompromised hosts. As the adherence of this organism both to host epithelial surfaces and to catheter and prosthetic surfaces appears to be important in the pathogenesis of superficial as well as systemic candidoses, the adhesion of 20 oral isolates of $C$. krusei and five oral isolates of $C$. albicans was compared with the following substrates: cultured (HeLa) epithelial cells, buccal epithelial cells (BEC) from healthy adults and bone marrow transplant patients, and acrylic (polymethylmethacrylate) surfaces. Animal experiments in Sprague Dawley rats were also conducted to evaluate the relative oral carriage rate of the two Candida spp. C. krusei isolates adhered in far greater numbers to acrylic surfaces than to either of the cell surfaces. Significant intra-species differences in $C$. krusei adhesion for acrylic surfaces were noted between 74 ( $39 \%$ ) of 190 pair comparisons in contrast to $18(9.5 \%)$ of 190 with HeLa surfaces $(\mathrm{p}<0.05)$. A positive correlation was also observed between the adhesion of $C$. krusei isolates to HeLa cells and acrylic surfaces. Five isolates of $C$. albicans showed very low adherence to $\mathrm{HeLa}$ surfaces when compared with BEC obtained from either healthy individuals or bone marrow transplant patients. The adherence of $C$. albicans to BEC from the healthy individuals was $c$. 12-fold greater than that of $C$. krusei, a figure similar to the relative murine oral carriage rate of the two Candida spp. However, the adhesion of C. albicans to BEC from bone marrow transplant patients was three-fold less than to BEC of healthy individuals whilst $C$. krusei adhesion remained the same, reflecting a possible selective colonisation process which may operate in these patient groups, possibly as a result of drug therapy. The current data, while confirming the inter- and intra-species differences in adherence of Candida spp. to host surfaces, illustrate that adherence-related factors may operate during colonisation of $C$. krusei on mucosal, catheter and prosthetic surfaces, in vivo in both health and disease.
\end{abstract}

\section{Introduction}

Adhesion to host surfaces is a prerequisite in the pathogenesis of many microbial infections. ${ }^{1}$ Despite the extensive data now available on bacterial adhesion, relatively few studies have focused on yeast adhesion, and most of these relate to Candida albicans. ${ }^{1}$ The adhesion of other Candida spp. has been little studied.

In recent years, infections with species other than $C$. albicans, such as C. krusei, C. tropicalis, C.parapsilosis, C. glabrata and C. guilliermondii, have been described increasingly both in compromised and noncompromised hosts. ${ }^{2}$ The increasing incidence of $C$. krusei infections, in particular, has been documented

Received 7 Dec. 1993; revised version accepted 12 April 1994. *Correspondence should be sent to Dr L. P. Samaranayake. clearly. ${ }^{3,4}$ One article, for instance, described systemic infection with fungaemia due to $C$. krusei in seven neonates in a department of neonatology. ${ }^{5} \mathrm{C}$. krusei has been reported as a pathogen in an intra-abdominal abscess, ${ }^{6}$ endocarditis, ${ }^{7}$ infective arthritis, ${ }^{8}$ ureteral obstruction, ${ }^{9}$ oesophagitis, ${ }^{10}$ disseminated disease,,${ }^{11-15}$, ocular infection, ${ }^{16}$ bone marrow transplant recipients ${ }^{17}$ and immunocompromised patients with cancer. ${ }^{18}$

Although $C$. krusei has been regarded traditionally as an organism of low virulence, this ever increasing incidence of $C$. krusei infections warrants further studies of its pathogenic potential. There is only a handful of investigations that evaluate the adherence potential of C. krusei ${ }^{19-21}$ these describe the adherence of the organism to buccal epithelial cells (BEC) and denture acrylic surfaces and a maximum of seven isolates was investigated. However, such studies may 
not reveal clearly the entire spectrum of this phenomenon, as there are differences in adherence amongst Candida isolates belonging to the same species. ${ }^{22}$ Furthermore, there are no studies to date on adhesion of $C$. krusei to BEC from healthy and diseased individuals or on its oral carriage in animal models.

Therefore, the present study was designed to compare the in-vitro adhesion of 20 oral isolates of C. krusei and five isolates of C. albicans, both to epithelial cells and to acrylic surfaces. C. albicans was chosen as the reference species as it is regarded as the most virulent medically important Candida sp. The epithelial surfaces studied included cultured HeLa epithelial cells, BEC obtained from healthy adults and bone marrow transplant patients. Acrylic was included as the inanimate surface representative of prosthodontic appliances or catheter surfaces. In-vivo studies in Sprague Dawley rats were also conducted to evaluate the oral carriage rate of the two Candida spp. in an attempt to relate these results to the in-vitro findings.

\section{Materials and methods}

\section{Candida isolates and growth conditions}

A total of 20 oral isolates of $C$. krusei and five of $C$. albicans was used in this study. All were from patients attending the Oral Medicine Clinic of the Glasgow Dental Hospital and School and were speciated by the germ tube tes ${ }^{23}$ and API 20C identification test kits (API Laboratory Products Ltd, Basingstoke, Hants). They were stored in distilled water at $-70^{\circ} \mathrm{C} .{ }^{24}$ All isolates were subcultured monthly on to Sabouraud's Dextrose Agar (SDA; Gibco Limited, Paisley) and maintained at $4^{\circ} \mathrm{C}$ during the experimental period. Purity of cultures was ensured by regular identification by standard techniques.

\section{Preparation of yeast inoculum}

A loopful from the stock culture of the test isolate was streaked on to SDA and incubated at $37^{\circ} \mathrm{C}$ for 18-20 h. A loopful of this fresh yeast growth was then transferred into glucose-supplemented (27 mM) Yeast Nitrogen Base (YNB; Difco, USA) and incubated at $37^{\circ} \mathrm{C}$ for $18-20 \mathrm{~h}$. The culture was then centrifuged at $3500 \mathrm{~g}$ for $10 \mathrm{~min}$ and the deposit was washed twice with phosphate-buffered saline (PBS; pH 7.2, 0.1 M). A final candidal suspension of $c .1 .0 \times 10^{7}$ yeasts $/ \mathrm{ml}$ was prepared by appropriate dilution and the number of yeasts/ml was monitored by microscopical counting in an improved Neubauer haemocytometer chamber (Hawksley Ltd, London).

\section{Preparation of HeLa epithelial cells}

HeLa cells (American Type Culture Collection, CCC2; Flow Laboratories, Irvine) were maintained in tissue-culture flasks as monolayers in RPM1-1640 (with L-glutamine and $25 \mathrm{~mm}$ HEPES buffer without sodium bicarbonate) supplemented with fetal bovine serum $10 \% \mathrm{v} / \mathrm{v}$, sodium bicarbonate $0.2 \% \mathrm{w} / \mathrm{v}$, penicillin G 100 units $/ \mathrm{ml}$ and streptomycin 100 units/ml (all from Sigma). ${ }^{25}$

The nutrient medium was discarded from the monolayer and the cells were washed once with sterile PBS and treated with $1 \mathrm{ml}$ of trypsin $0.15 \%$ solution until the cells detached. The resulting cell pellet was suspended in 2-3 ml of warm RPM1-1640 working medium and $150-200 \mu \mathrm{l}$ of this cell suspension was seeded aseptically into each well ( $35 \mathrm{~mm}$ diameter) of a multi-well tissue-culture tray (Sterilin, Middlesex) containing a sterile coverslip $(22 \times 22 \mathrm{~mm})$ and $3 \mathrm{ml}$ of working medium. The cells were then incubated at $37^{\circ} \mathrm{C}$ in an atmosphere of air $95 \%$ and $\mathrm{CO}_{2} 5 \%$ for 2-3 days until confluent monolayers formed on the glass coverslips. Before the adhesion assay, the nutrient medium was discarded and the monolayers were washed once with PBS.

\section{Preparation of buccal epithelial cells}

BEC were collected by gently rubbing the cheek mucosa of 16 healthy adult volunteers (eight males, eight females) with sterile swabs and then rotating the swabs in $10 \mathrm{ml}$ of PBS. The cells were washed three times in PBS by centrifugation, pooled and resuspended to a concentration of $1 \times 10^{5}$ cells $/ \mathrm{ml}$ by haemocytometer counting.

BEC from bone marrow transplant patients were used for some experiments. These were obtained from patients at the Queen Mary Hospital, Hong Kong. The patients were receiving a regimen of regular chlorhexidine gluconate $0.2 \%$ mouthwashes and the triazole antifungal fluconazole $(800 \mathrm{mg} /$ day by oral or intravenous route) during the cell collection period. Five or six adult patients (two females, four males) were sampled every 2 weeks for a period of 6 weeks by gently rubbing the cheek mucosa of each patient with two sterile cotton wool swabs. The BEC were then collected in $10 \mathrm{ml}$ of PBS by manual agitation of the swabs, washed three times in PBS by centrifugation, pooled and adjusted to $1.0 \times 10^{5}$ cells $/ \mathrm{ml}$ by haemocytometer counting. The same cohorts of patients and healthy individuals (controls) were used throughout the adhesion assay, conducted as described below.

All BEC from both groups were screened microscopically before the assay for attached yeasts. If adherent yeasts were present the cell suspension was discarded.

\section{Adhesion assays}

HeLa cells. The adhesion of yeasts to cultured epithelial cells was determined according to the method of Samaranayake and MacFarlane. ${ }^{25}$ Briefly, washed HeLa cell monolayers on glass coverslips were 
incubated with $1 \mathrm{ml}$ of $C$. krusei or $C$. albicans suspension $\left(1 \times 10^{7}\right.$ yeasts $\left./ \mathrm{ml}\right)$ in $\mathrm{PBS}$ at $37^{\circ} \mathrm{C}$ for $1 \mathrm{~h}$ in a shaking water bath at $40 \mathrm{rpm}$. The suspension was then removed aseptically and the monolayers with the adherent yeasts were washed twice with sterile PBS for $30 \mathrm{~s}$ by gentle manual agitation and fixed in formaldehyde $10 \%$ for $5 \mathrm{~h}$. The monolayers were subsequently air-dried, gram-stained and mounted on glass microscope slides. All samples were set up in duplicate for each experiment and the yeasts attached to the monolayers were quantified as described below. Each experiment was repeated on three separate occasions.

Buccal epithelial cells. The assay was performed according to the method of Kimura and Pearsall. ${ }^{26}$ Briefly, equal volumes $(0.5 \mathrm{ml})$ of $\operatorname{BEC}\left(1.0 \times 10^{5}\right.$ cells $/ \mathrm{ml})$ and Candida suspensions $\left(1.0 \times 10^{7}\right.$ cells $\left./ \mathrm{ml}\right)$ were mixed and incubated at $37^{\circ} \mathrm{C}$ for $1 \mathrm{~h}$ in a shaking water bath at $40 \mathrm{rpm}$. The cells were then harvested on $12-\mu \mathrm{m}$ pore polycarbonate filters (Costar, MA, USA) and washed with $30 \mathrm{ml}$ of PBS to remove unattached yeasts. The washed cells were fixed with methanol, airdried and stained with crystal violet for $30 \mathrm{~s}$, washed with tap water and air-dried once more. These filters were mounted on glass slides and the number of adherent yeasts quantified as described below. This assay was performed on three separate occasions.

Experiments with BEC from bone marrow transplant patients were limited to only single isolates of $C$. krusei (CK9) and C. albicans (CA2) because of the practical difficulties in harvesting large quantities of cells from these individuals. The adhesion of these two Candida isolates to pooled BEC from five or six bone marrow transplant patients and 16 healthy individuals was compared. This assay was performed in exactly the same manner as above.

Acrylic. Acrylic strips for the assay were prepared according to the method of Samaranayake and MacFarlane. ${ }^{27}$ Transparent self-polymerising acrylic powder (polymethyl methacrylate powder; Dental Fillings Ltd., London) $1.5 \mathrm{~g}$ was spread on a glass slide covered with aluminium foil and the monomer liquid was poured on to the surface; immediately, a second slide was placed on top of the polymerising mixture and firmly secured. The resultant acrylic strips were cleaned and cut into $5 \times 5 \mathrm{~mm}$ squares and used in the experiments.

The adherence of yeasts to acrylic surfaces was quantified as described previously. ${ }^{27}$ Briefly, $0.4 \mathrm{ml}$ of the prepared yeast suspension $\left(1 \times 10^{7}\right.$ cells $\left./ \mathrm{ml}\right)$ was dispensed to a well of a sterile serology plate and an acrylic strip was placed vertically in the well. After incubation at $37^{\circ} \mathrm{C}$ for $1 \mathrm{~h}$, the strips were removed, washed twice in sterile distilled water, air-dried and stained with crystal violet and Gram's iodine. The strips were then mounted on glass slides and adherent yeasts were quantified as described below. All values quoted represent mean figures derived from three independent assays with duplicate determinations on each occasion.

\section{Microscopy}

The number of adherent yeasts on the HeLa cell monolayers and the acrylic strips was estimated by the principle of stratified random sampling. ${ }^{25,27}$ Thirty fields were counted for each sample. As the samples were set up in duplicate for each experiment, the mean number of yeasts $/ 60$ fields was finally expressed as yeasts $/ 0.561 \mathrm{~mm}^{2}$ of surface area in the case of HeLa cells and acrylic surfaces. For the BEC assay, the number of yeasts which were adherent to $100 \mathrm{BEC}$ was determined by light microscopy at $\times 400$ magnification. Counts on two separate filters were performed for each sample.

\section{Animal experiments}

The murine model of Jones and Russell ${ }^{28}$ was used. Ten young male Sprague Dawley rats, $200-300 \mathrm{~g}$ in weight, were divided equally into two groups for inoculation with either $C$. krusei (CK9) or C. albicans (CA2). All animals received tetracycline hydrochloride $1 \%$ in drinking water and a carbohydrate-rich diet (carbohydrate $62 \%$, proteins $33 \%$, vitamins and minerals $5 \%$ ) and were inoculated orally three times per week with $0.1 \mathrm{ml}$ of the appropriate yeast suspension containing $c .(1-2) \times 10^{8}$ yeasts $/ \mathrm{ml}$. Once a week, 3 days after the last inoculation, oral swabs were obtained from each rat, the contents of which were thoroughly dispersed in $5 \mathrm{ml}$ of sterile distilled water. The number of colony forming units of the Candida isolates in this suspension were assessed by spiral plating (Spiral Systems, OH, USA) $50 \mu$ lon to a Sabouraud's dextrose agar plate which was incubated at $37^{\circ} \mathrm{C}$ for $48 \mathrm{~h}$ and the resultant colonies were quantified.

\section{Statistical analysis}

The data from the adhesion assays were analysed by analysis of variance (ANOVA). In particular, the ANOVA test was used to determine the significant differences, if any, between species, isolates and surfaces. The Student-Newman-Keuls test was performed to study pairwise comparisons between isolates within each species-surface combination. The correlation between yeast adherence to all surfaces studied was determined by the StatWorks statistics computer package.

\section{Results}

\section{Adhesion}

C. krusei to epithelial surfaces. The adhesion of $20 \mathrm{C}$. krusei isolates grown in YNB to HeLa epithelial surfaces is shown in fig. 1. All C. krusei isolates adhered well to HeLa cells although wide variations in values were seen; the highest and lowest mean values were 141.7 and $26 \cdot 1$. On further pairwise comparisons, to evaluate intra-species differences in adhesion by the 


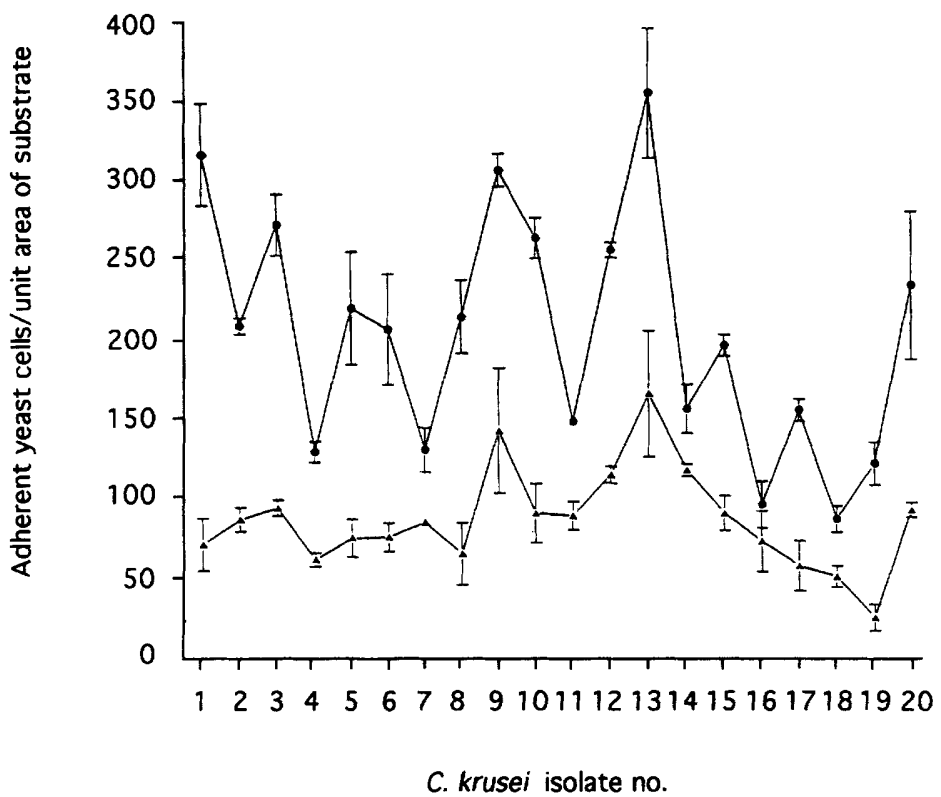

Fig. 1. The adhesion of $20 \mathrm{C}$. krusei isolates to HeLa epithelial cells (A) and acrylic surfaces ( $)$. Each point represents a mean of three experiments conducted on separate occasions; bar, SEM.

Table I. The adhesion of C. krusei and C. albicans to buccal epithelial cells of healthy individuals

\begin{tabular}{|c|c|c|c|}
\hline $\begin{array}{l}\text { C. krusei } \\
\text { isolate no. }\end{array}$ & $\begin{array}{l}\text { Mean (SD) number of } \\
\text { yeast } / 100 \mathrm{BEC}\end{array}$ & $\begin{array}{l}\text { C. albicans } \\
\text { isolate no. }\end{array}$ & $\begin{array}{l}\text { Mean }(\mathrm{SD}) \text { number of } \\
\text { yeast } / 100 \mathrm{BEC}\end{array}$ \\
\hline CK6 & $10.33(3.55)$ & CAl & $113 \cdot 33(8 \cdot 73)$ \\
\hline CK9 & $12.83(8 \cdot 77)$ & CA2 & $153.66(31 \cdot 10)$ \\
\hline CK13 & $18.33(10.33)$ & CA3 & $161.33(29.82)$ \\
\hline CK18 & $14.16(1.47)$ & CA4 & $206.66(44.78)$ \\
\hline CK19 & $12 \cdot 50(3 \cdot 14)$ & CA5 & $142.50(47.06)$ \\
\hline Mean $\pm S D$ & $13.63 \pm 5.45$ & Mean \pm SD & $155.49 \pm 32.29$ \\
\hline
\end{tabular}

The results are expressed as means of duplicate counts for each experiment, conducted on three separate occasions.

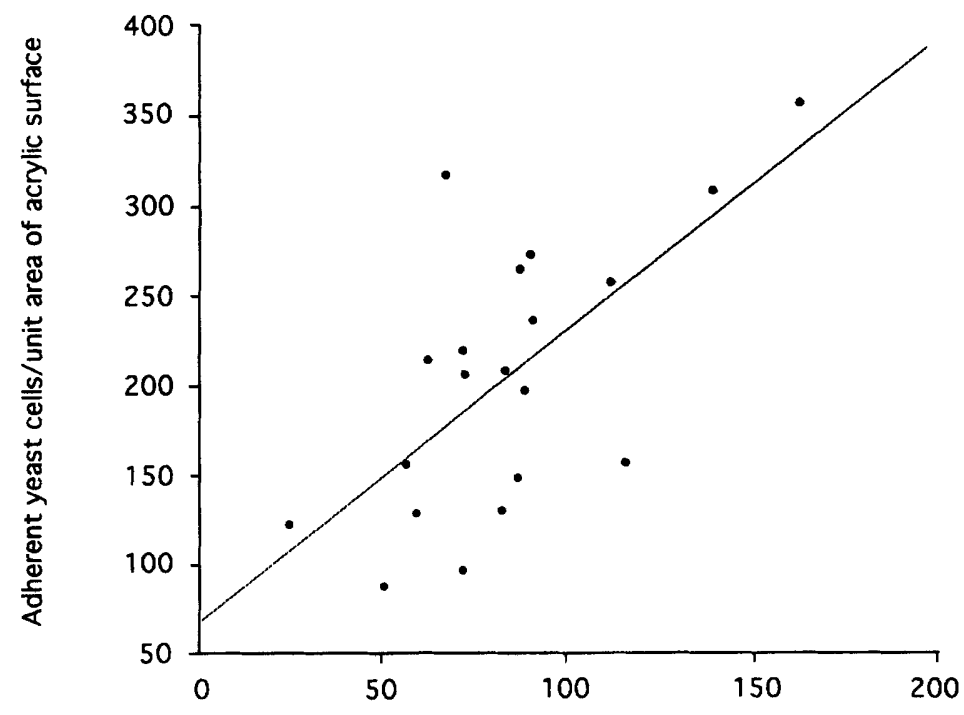

Adherent yeast cells/unit area of HeLa cell surface

Fig. 2. The relationship between the adhesion of $C$. kruse isolates to acrylic and HeLa epithelial cell surfaces. Correlation coefficient $r=0 \cdot 66$, $\mathrm{p}<0.001$.

Student-Newman-Keuls test, significant differences $(p<0.05)$ in adhesion between $18(9.5 \%)$ of 190 pairs of $C$. krusei were noted.
The foregoing data and those from acrylic studies (see below) were used to select five isolates of C. krusei with high, low and moderate degrees of adherence and 


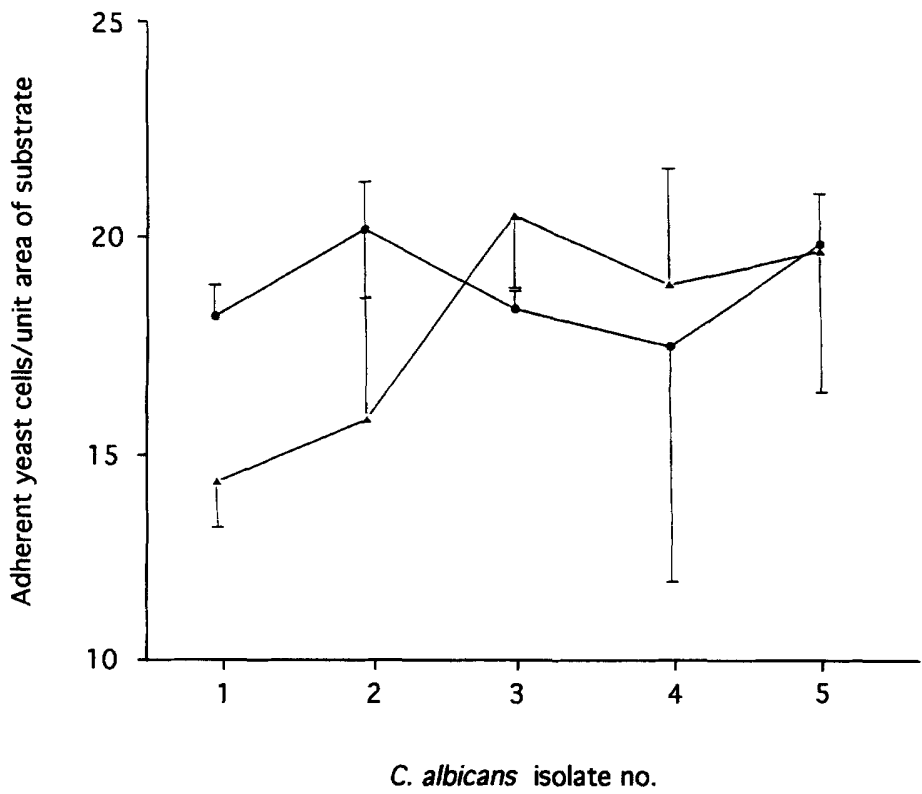

Fig. 3. The adhesion of $C$. albicans isolates to HeLa epithelial cells $(\boldsymbol{\Delta})$ and acrylic surfaces $(\boldsymbol{\bullet})$. Each point represents a mean of three experiments conducted on separate occasions; bar, SEM.

Table II. The relative adhesion of $C$. albicans (CA2) and C. krusei (CK9) to pooled BEC from healthy and bone marrow transplant patients (BMT)

\begin{tabular}{|c|c|c|c|c|c|c|}
\hline \multirow[b]{3}{*}{$\begin{array}{l}\text { Experiment } \\
\text { no. }\end{array}$} & \multicolumn{6}{|c|}{ Mean number of yeast cells/100 BEC from } \\
\hline & \multicolumn{3}{|c|}{ healthy individuals $(\mathrm{n}=16)$} & \multicolumn{3}{|c|}{ BMT patients $(\mathrm{n}=5$ or 6$)$} \\
\hline & $\begin{array}{l}\text { C. albicans } \\
\text { (CA2) (a) }\end{array}$ & $\begin{array}{l}\text { C. krusei } \\
\text { (CK9) (k) }\end{array}$ & $\begin{array}{l}\text { Ratio } \\
(\mathrm{a}: \mathrm{k})\end{array}$ & $\begin{array}{l}\text { C. albicans } \\
\text { (CA2) (a) }\end{array}$ & $\begin{array}{l}\text { C. krusei } \\
\text { (CK9) (k) }\end{array}$ & $\begin{array}{l}\text { Ratio } \\
(\mathrm{a}: \mathrm{k})\end{array}$ \\
\hline 1 & $149 \cdot 50$ & $15 \cdot 50$ & $9 \cdot 64$ & $30 \cdot 20$ & $6 \cdot 80$ & $4 \cdot 44$ \\
\hline 2 & 182.00 & 5.00 & $36 \cdot 40$ & 84.80 & 18.30 & 4.63 \\
\hline 3 & $129 \cdot 50$ & $23 \cdot 00$ & 5.63 & $54 \cdot 30$ & $14 \cdot 50$ & 3.74 \\
\hline Mean & $153.66^{*}$ & 14.50 & $10 \cdot 59$ & $56 \cdot 43^{*}$ & 13.20 & $4 \cdot 27$ \\
\hline
\end{tabular}

Results are expressed as means of duplicate counts of $100 \mathrm{BEC}$, for each experiment.

*Significantly different at $\mathrm{p}<0.05$.

these isolates were used in BEC studies. The latter five isolates of $C$. krusei demonstrated a lesser degree of adhesion to BEC from healthy donors than to $\mathrm{HeLa}$ cells, although strict comparisons could not be made because of the difficulty in quantifying the total area of BEC. The mean adhesion of C. krusei isolates was in the range $10-18$ yeasts/100 $\mathrm{BEC}$, indicating little variation between the isolates $(\mathrm{p}>0.05)$ (table I).

$C$. krusei to acrylic surfaces. The remarkably high adherence of the $20 C$. kruse $i$ isolates to acrylic surfaces is shown in fig. 1. As in the case of epithelial surfaces, C. krusei isolates demonstrated substantial variations in their adhesion to the acrylic strips. For example, the highest and the lowest values were 354.3 and 96.3 yeasts/unit area. On statistical analysis, significant intra-species differences $(p<0.05)$ in adhesion between $74(39 \%)$ of 190 pair comparisons were noted in contrast to $9.5 \%$ observed with the HeLa surfaces.

Relative adhesion of C. krusei to HeLa cells and acrylic surfaces. When the relative adhesion of $C$. krusei isolates to unit areas of $\mathrm{HeLa}$ and acrylic surfaces were compared the affinity of yeasts to the latter was two-fold greater than to the HeLa cell surface $(p<0.001)$. Furthermore, there was a significant positive correlation between the adhesion of $C$. krusei isolates to the two surfaces $(\mathrm{p}<0.001, \mathrm{r}=$ 0.663 ; fig. 2).

C. albicans to epithelial surfaces. The adhesion of $C$. albicans isolates to HeLa epithelial surfaces is shown in fig. 3. Intra-species variations in adherence values were minimal; the highest and lowest mean adherence values were $14 \cdot 3$ and $20 \cdot 4$. No significant differences in adhesion between $C$. albicans isolates were noted. Furthermore, the mean adherence values of these isolates to $\mathrm{HeLa}$ epithelial cells was remarkably lower (17 for C. albicans and 86 for C. krusei) than for the $C$. krusei isolates.

The results of studies with $C$. albicans and BEC indicated varying mean adherence values with different isolates. Significant differences in adhesion were noted between two pairs of $C$. albicans isolates as opposed to no significant difference between $C$. krusei isolates. In addition, $C$. albicans isolates demonstrated almost 12fold greater affinity for BEC than C. krusei isolates 
Table III. Post-inoculation oral carriage of C. krusei and C. albicans in SpragueDawley rats

\begin{tabular}{|c|c|c|c|c|c|c|c|}
\hline \multirow{2}{*}{ Candida sp. } & \multirow{2}{*}{ Rat no. } & \multicolumn{6}{|c|}{ Oral carriage $\left(\mathrm{cfu} \times 10^{1} / \mathrm{ml}\right)$} \\
\hline & & Week 1 & Week 2 & Week 3 & Week 4 & Mean & SEM \\
\hline \multirow[t]{5}{*}{ C. krusei } & 1 & $2 \cdot 03$ & $4 \cdot 06$ & $2 \cdot 03$ & 0.00 & $2 \cdot 03$ & 0.83 \\
\hline & 2 & 2.03 & 4.06 & $4 \cdot 06$ & 6.09 & 4.06 & 0.83 \\
\hline & 3 & $4 \cdot 06$ & $6 \cdot 09$ & $0-00$ & $2 \cdot 03$ & 3.05 & $1 \cdot 31$ \\
\hline & 4 & $2 \cdot 03$ & 4.06 & $2 \cdot 03$ & $4 \cdot 06$ & 3.05 & 0.59 \\
\hline & 5 & 0.00 & $0 \cdot 00$ & $2 \cdot 03$ & 0.00 & 0.51 & 0.51 \\
\hline \multirow[t]{5}{*}{ C. albicans } & 1 & $24 \cdot 39$ & 26.42 & 34.55 & $30 \cdot 48$ & $28 \cdot 96$ & $2 \cdot 25$ \\
\hline & 2 & $26 \cdot 42$ & 28.45 & $30 \cdot 48$ & $32 \cdot 52$ & $29 \cdot 47$ & $1 \cdot 31$ \\
\hline & 3 & $30 \cdot 48$ & $24 \cdot 39$ & 36.58 & $34 \cdot 55$ & $31 \cdot 50$ & $2 \cdot 69$ \\
\hline & 4 & $24 \cdot 39$ & $32 \cdot 52$ & 28.45 & $30 \cdot 48$ & 28.96 & $1 \cdot 74$ \\
\hline & 5 & 28.45 & $28 \cdot 45$ & $26 \cdot 42$ & $30 \cdot 48$ & $28 \cdot 45$ & 0.83 \\
\hline
\end{tabular}

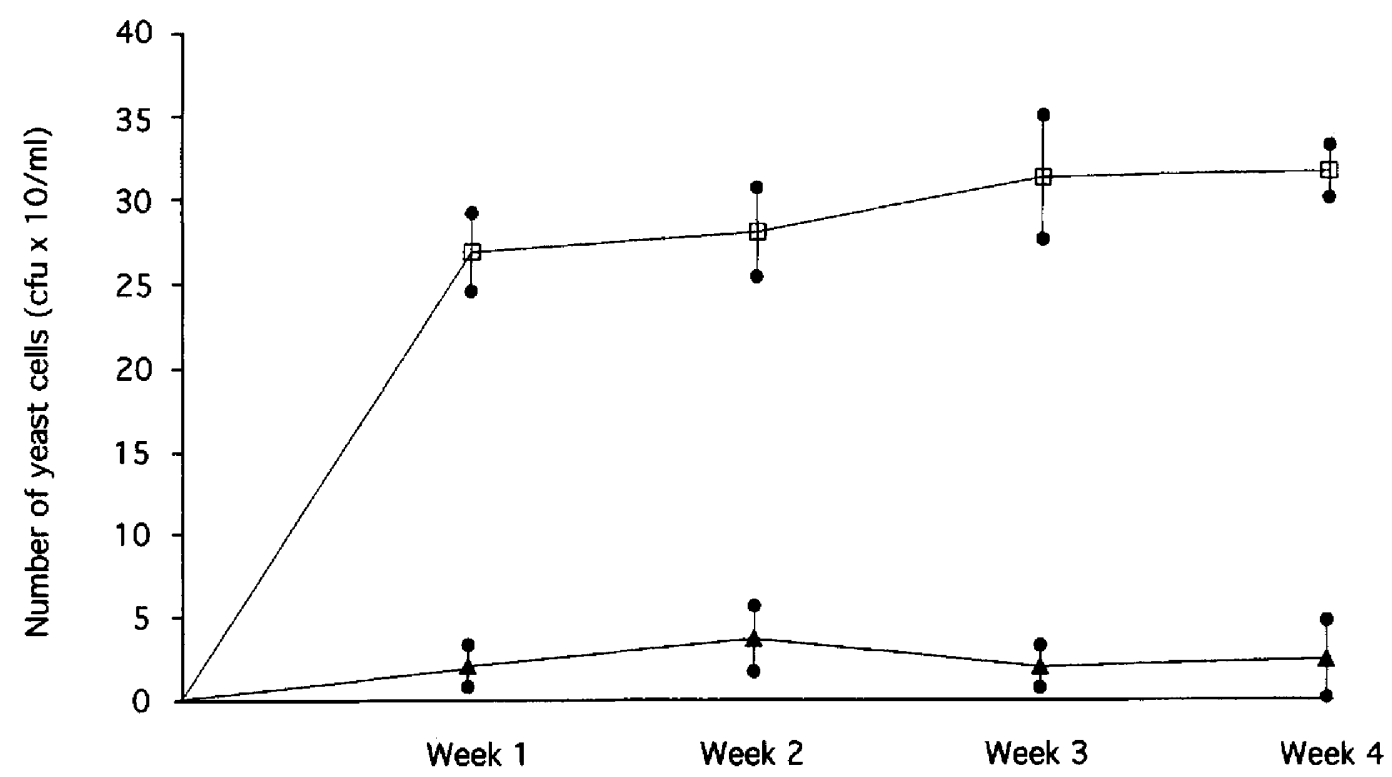

Fig. 4. Oral carriage of C. albicans CA2 $(\square)$ and $C$. krusei $\mathrm{CK} 9(\mathbf{\Delta})$ in Sprague Dawley rats over a period of 4 weeks. Each point represents the mean carriage rate (and SEM) in five rats. The rats were inoculated orally three times a week with $0.1 \mathrm{ml}$ of a suspension containing $1.0 \times 10^{8}$ yeasts $/ \mathrm{ml}$ and swabs were taken 3 days after the last inoculation.

(table I), in contrast to observations with HeLa cells (see above).

The adhesion of a $C$. albicans isolate (CA2) and a $C$. krusei isolate (CK9) to BEC obtained both from healthy individuals and bone marrow transplant patients is shown in table II. When the relative adhesion of the two Candida spp. to BEC from the donor groups was compared, $C$. albicans exhibited significantly lower adherence to cells from the patients $(p<0.05)$ although there was no significant difference in the adhesion of $C$. krusei to these cell types. Thus, in relative terms, the avidity of $C$. krusei to BEC of bone marrow transplant patients appeared to be $c$. threefold greater than to those from healthy individuals.

C. albicans isolates to acrylic and HeL a cell surfaces. All C. albicans isolates demonstrated remarkably similar adherence to the acrylic surfaces (range 17-20 yeasts/unit area) with no significant intra-species difference in adhesion. When the relative adhesion of C. albicans isolates to acrylic and HeLa cell surfaces were compared, the affinity of yeasts for both surfaces did not vary widely and there was no significant correlation between the adhesion of the isolates to the two surfaces.

Relative adhesion of $C$. krusei and $C$. albicans to $\mathrm{HeLa}$ cell and acrylic surfaces. C. krusei isolates adhered in significantly greater numbers to both $\mathrm{HeLa}$ cell and acrylic surfaces than did $C$. albicans isolates ( $\mathrm{p}<0.001$ ). Thus, the mean adhesion of $C$. krusei to HeLa cell and acrylic surfaces was 202 and 86 yeasts/unit area, respectively, compared with 17 and 18 yeasts/unit area in the case of $C$. albicans.

\section{Oral carriage of $C$. albicans and $C$. krusei in rats}

The oral carriage rate of both Candida spp. is shown in table III and fig. 4. The recovery of $C$. krusei was consistently and significantly less than that of $C$. albicans throughout the experimental period ( $<<0.05) ; C$. albicans demonstrating almost 11 -fold greater colonisation potential than $C$. krusei.

Gross oral lesions were not detected in either group 
of animals at the termination of the experimental period. Histopathological examination was not performed.

\section{Discussion}

Candida spp. are common opportunist yeasts in the oral cavity, gastrointestinal tract and the vagina of many normal individuals. ${ }^{29}$ They are isolated frequently from the palatal mucosa and the inert, acrylic denture fitting surfaces of patients with denture stomatitis, ${ }^{30,31}$ and are increasingly associated with nosocomial septicaemia originating from intravascular catheters. ${ }^{32}$ Although the transition of $C$. albicans from saprophytism to pathogenic parasitism remains largely unexplained, it is widely recognised that the ability of these organisms to adhere to susceptible host tissues and inert prostheses, such as dentures or medical implants and catheters, is an essential prerequisite for a transient or a sustained association with the host. ${ }^{2,3}$

In contrast to $C$. albicans, which is considered to be the most pathogenic and hence the most virulent species, $C$. kruse $i$ is a less well known species currently gaining clinical interest as an emerging pathogen. For example, $C$. krusei infections of various organs such as the gut, ${ }^{33}$ the eye, ${ }^{16}$ the urethra ${ }^{9}$ and many others ${ }^{4,11-15,17}$ have been reported.

Although there has been a multitude of studies with C. albicans, ${ }^{1,34}$ only a few investigators ${ }^{19-21}$ have examined the adherence of $C$. krusei to BEC and the maximum number of isolates investigated was seven. ${ }^{20}$ Several isolates belonging to the same Candida spp. need to be studied to obtain a broad perspective of their virulence parameters, as intra-species variations in attributes such as adherence are well known. ${ }^{22}$ As far as we are aware, there have been no reports on the adhesion parameters of a collection of clinical isolates of $C$. krusei either to cultured epithelial surfaces or to epithelial cells from compromised hosts. Similarly, the oral carriage rate of this organism in an animal model has not been studied previously.

HeLa epithelial cells were chosen to screen all the $C$. kruse $i$ isolates as they offer an uncontaminated surface with minimal variability, ${ }^{35}$ thus rendering the individual results broadly comparable. In contrast, BEC from healthy and diseased hosts were used to elicit baseline data in an attempt to seek relative differences, if any, in candidal adhesion to these cell types. Since a number of parameters are known to affect the adhesion of organisms to $\mathrm{BEC},{ }^{1,36}$ the possible variations in the quality of cells were minimised by collecting and pooling cells from the same group of donors at a specific time of the day and using them within $2 \mathrm{~h}$ of collection.

The adhesion of $C$. krusei to BEC was significantly less than that of $C$. albicans, the species most often implicated in human infection. These results agree with those of Tobgi $^{20}$ and King et al.,${ }^{21}$ in which the hierarchy of adhesion of Candida spp. to BEC was similar. Furthermore, in the study by Tobgi, ${ }^{20}$ there was an 11-fold increase in the adherence of $C$. albicans to BEC compared with $C$. krusei, a result identical to that of the current study, testifying to the concordance of the experimental method. Generally, all studies revealed minimal adhesion of $C$. krusei to human $\mathrm{BEC}$, tending to confirm the low virulence potential of this yeast.

These in-vitro findings are borne out by the murine oral carriage rate of the two Candida spp. over a period of 4 weeks; despite repeated inoculation of equal doses of the yeasts, C. krusei carriage was almost 12 -fold less than that of $C$. albicans. While this remarkable similarity between the in-vivo carriage rate and the invitro adhesion potential of the two Candida spp. should not be construed solely as a function of the latter variable, due to the complexity of the oral environment, our results tend to strengthen the belief that adhesion phenomena play a decisive role in oral candidal colonisation.

From the current data it is evident that there are small $(4 \cdot 2 \%)$ but significant intra-species differences in the adherence of $C$. krusei to HeLa epithelial cells, although this figure rose to $72 \%$ with acrylic surfaces. It is difficult to offer a reason for this discrepancy but one possibility may be the hydrophobic forces which operate to a very great extent in the adhesion of Candida to inert surfaces (see below).

The adherence of 20 clinical isolates of $C$. krusei to acrylic strips was remarkably high $\left(364\right.$ cells $\left./ \mathrm{mm}^{2}\right)$, a result similar to that obtained by Tobgi $^{20}$ (395 cells $/ \mathrm{mm}^{2}$ ) with seven strains of $C$. krusei. The higher adhesion value obtained by the latter worker may be due to the culture medium, which contained $550 \mathrm{~mm}$ sucrose instead of the $27 \mathrm{~mm}$ glucose used in the present study. It is known that adhesion of C. albicans grown in sucrose media is enhanced considerably when compared with yeasts grown in media with either glucose or low concentrations of other sugars. ${ }^{25,37}$ This is considered to be due to the changes in the yeast cell surface components with resultant formation of extracellular fibrillar material which promotes candidal adherence. ${ }^{38}$

Compared with C. albicans, which adhered in almost equal numbers to both HeLa cells and acrylic surfaces, C. krusei demonstrated 2-4-fold greater affinity for acrylic than for HeLa cell surfaces. This may be explicable in terms of the significantly higher (fivefold) cell surface hydrophobicity of $C$. krusei compared with $C$. albicans (Y. H. Samaranayake, unpublished data). Cell surface hydrophobicity and other nonspecific forces may promote the attachment of the yeast to plastic medical devices, such as indwelling catheters and prostheses..$^{39}{ }^{41}$ Minagi et al.${ }^{40}$ compared the surface hydrophobicity of six Candida spp. by contact angle measurement and adherence to hydrocarbons and observed higher adherence of $C$. krusei than $C$. albicans. Others have observed a significant positive correlation between the adherence of Candida 
spp. to acrylic surfaces and their affinity for hexadecane-an inert organic surface. ${ }^{41}$ Furthermore, Nikawa et al..$^{42}$ conducted comparative studies on the adherence of Candida spp. to surface-modified glass and found $C$. krusei to be the most hydrophobic with the least zeta potential and the most adherent to glass compared to a panel of Candida spp., including $C$. albicans. Hence it would seem that the significantly higher adherence of $C$. krusei to acrylic, observed in this study, is to a great extent a reflection of its hydrophobicity.

Although, in the current study, the adherence of Candida spp. to acrylic (polymethylmethacrylate) surfaces was studied, these results could arguably be extrapolated to include catheter surfaces, as it is known that the adherence of yeasts to polymers such as teflon and other material of which catheters are made, is directly proportional to their contact angle and hydrophobicity. ${ }^{39}$ If this were the case, then because of its superior hydrophobicity, $C$. krusei should more preferentially attach to and colonise catheter surfaces than C. albicans. Indeed, in a recent in-vitro study, Hawser and Douglas ${ }^{43}$ demonstrated that $C$. krusei has a significantly greater potential to form biofilms than $C$. albicans on polyvinylchloride catheter material, which may be due to its high affinity for inert surfaces.

In clinical terms, the most interesting finding in this study was the significant reduction in the adherence of C. albicans to BEC from bone marrow transplant patients in comparison to cells from healthy individuals (table II). This observation could be explicable in terms of the topical and systemic drug regimens of the patient group, for it is known that oral rinses of

\section{References}

1. Kennedy MJ. Adhesion and association mechanisms of Candida albicans. In: McGinnis MR (ed) Current topics in medical mycology. New York, Springer Verlag. 1987: 73-169.

2. Odds FC. Candida and candidosis, 2nd edn. London, Bailliere Tindall. 1988

3. Bodey GP. Candidiasis: pathogenesis, diagnosis and treatment, 2nd edn. New York, Raven Press. 1993: 6

4. Samaranayake YH, Samaranayake LP. Candida krusei: biology, epidemiology, pathogenicity and clinical manifestations of an emerging pathogen. J Med Microbiol 1994; 41: 295-310.

5. Hendrick W, Schonborn C, Spencker FB, Huckel-D. Infection caused by Candida krusei in newborn infants. Paediatr Pathol 1989; 24: 289-295.

6. Gordon RA, Simmons BP, Appelbaum PC, Aber RC. Intraabdominal abscess and fungemia caused by Candida krusei. Arch Intern Med 1980; 140: 1239-1240.

7. Rubinstein E, Noriega ER, Simberkoff MS, Holzman R, Rahal JJ. Fungal endocarditis : analysis of 24 cases and review of the literature. Medicine 1975; 54: 331-344.

8. Nguyen VQ, Penn RL. Candida krusei infectious arthritis. A rare complication of neutropenia. Am J Med 1987; 83: 963-965.

9. Thomalla JV, Steidle CP, Leapman SB, Filo RS. Ureteral obstruction of a renal allograft secondary to Candida krusei. Transplant Proc 1988; 20 : 551-554.

10. Mathieson R, Dutta SK. Candida esophagitis. Dig Dis Sci 1983; 28: $365-370$.

11. Meunier-Carpentier F, Kiehn TE, Armstrong D. Fungemia in the immunocompromised host. Changing patterns, antigenemia, high mortality. Am J Med 1981; 71: 363-370. chlorhexidine gluconate $0.2 \%$ and fluconazole therapy result in $16-54 \%^{44}$ and $48-52 \%^{45}$ reduction of $C$. albicans adherence to BEC, respectively. However, we cannot offer an explanation for the almost equal mean adhesion values of $C$. krusei to buccal cells from both healthy and diseased hosts, as no studies are available on the effect of antifungal agents on its adhesion. As $C$. krusei exhibits surface properties ${ }^{4.46}$ and genomic characteristics ${ }^{47,48}$ which are remarkably dissimilar to C. albicans, this is an area worthy of further study. However, the results of this study indicate that the drug regimens commonly used in bone marrow transplant patients may select out uncommon organisms such as $C$. krusei, in preference to C. albicans. For example, Wingard et al. ${ }^{17}$ recently found C. krusei to be the chief candidal pathogen in $2.6 \%$ of 419 bone marrow transplant patients, compared to $2.4 \%$ infected by C. albicans. Hence it is tempting to speculate that the modulation of candidal adhesion dynamics by drug therapy, ${ }^{44,45}$ as well as the intrinsic resistance of C. krusei to the newer triazole fluconazole, ${ }^{49-50}$ may result in the increasing emergence of $C$. krusei infections. ${ }^{4}$

In conclusion, the current results taken together indicate that adhesion mechanisms play a significant role in the colonisation of $C$. krusei in both diseased and healthy hosts. However, further research is warranted, particularly to study the intriguing interactions of this and other Candida spp. in bone marrow transplant and other compromised patient groups.

This study was supported by a grant from the University of Hong Kong Committee for Research and Conference Grants. Y.H.S. was supported by a studentship from the University of Hong Kong.

12. Myerowitz RL, Pazin GJ, Allen CM. Disseminated candidiasis. Changes in incidence, underlying diseases, and pathology. Am J Clin Pathol 1977; 68: 29-38.

13. Young RC, Bennet JE, Geelhoed GW, Levine AS. Fungemia with compromised host resistance. A study of 70 cases. Ann Int Med 1974; 80: 605-612.

14. Jacobs MI, Magid MS, Jarowski CI. Disseminated candidiasis: newer approaches to early recognition and treatment. Arch Dermatol 1980; 116: 1277-1279.

15. Rose HD, Varkey B. Deep mycotic infection in the hospitalized adult: a study of 123 patients. Medicine $1975 ; 54: 499-507$.

16. McQuillen DP, Zingman BS, Meunier F, Levitz SM. Invasive infections due to Candida krusei: Report of ten cases of fungemia that include three cases of endophthalmitis. Clin Infect Dis 1992; 14: 472-478.

17. Wingard JR, Merz WG, Rinaldi MG, Johnson TR, Karp JE, Saral R. Increase in Candida krusei infection among patients with bone marrow transplantation and neutropenia treated prophylactically with fluconazole. $N$ Engl $J$ Med 1991; 325: 1274-1277.

18. Persons DA, Laughlin M, Tanner D, Perfect J, Gockerman JP, Hawthorn JW. Fluconazole and Candida krusei fungemia. N Engl J Med 1991; 325: 1315.

19. Critchley IA, Douglas LJ. Differential adhesion of pathogenic Candida species to epithelial and inert surfaces. FEMS Microbiol Lett 1985; 28: 199-203.

20. Tobgi RS. Differences in the pathogenic potential of Candida species, especially $C$. albicans. PhD Thesis. Faculty of Medicine, University of Glasgow. 1989.

21. King RD, Lee JC, Morris AL. Adherence of Candida albicans and other Candida species to mucosal epithelial cells. Infect Immun 1980; 27: 667-674. 
22. Samaranayake LP, MacFarlane TW (eds). Oral candidosis. London, Wright. 1990.

23. Lodder J. The yeasts: a taxonomic study, 2nd edn. Amsterdam, North Holland. 1970.

24. Silverman S, Migliorati CA, Epstein JB, Samaranayake LP. Laboratory diagnosis of oral candidosis. In: Samaranayake LP, MacFarlane TW (eds) Oral candidosis. London, Wright. 1990: 213-237.

25. Samaranayake LP, MacFarlane TW. The effect of dietary carbohydrates on the in-vitro adhesion of Candida albicans to epithelial cells $J$ Med Microbiol 1982; 15: 511-517.

26. Kimura LH, Pearsall NN. Adherence of Candida albicans to human buccal epithelial cells. Infect Immun 1978; 21: 64-68.

27. Samaranayake LP, MacFarlane TW. An in-vitro study of the adherence of Candida albicans to acrylic surfaces. Arch Oral Biol 1980; 25: 603-609.

28. Jones JH, Russell C. The histology of chronic candidal infection of the rat's tongue. $J$ Pathol 1974; 113: 97-100.

29. Hurley R, de Louvois J, de Mulhall A. Yeasts as human and animal pathogens. In: Rose AH, Harrison JS (eds) The yeasts, vol 1, 2nd edn. London, Academic Press. 1987: 207-281.

30. Olsen I. Denture stomatitis. Occurrence and distribution of fungi. Acta Odontol Scand 1974; 32: 329-333.

31. Budtz-Jorgensen E. The significance of Candida albicans in denture stomatitis. Scand J Dent Res 1974; 82 : 151-190.

32. Goldmann DA, Pier GB. Pathogenesis of infections related to intravascular catheterization. Clin Microbiol Rev 1993; 6: 176-192.

33. Merz WG, Karp JE, Schron D, Saral R. Increased incidence of fungemia caused by Candida krusei. J Clin Microbiol 1986; 24: $581-584$.

34. Segal E, Lehrman O, Dayan D. Adherence in vitro of various Candida species to acrylic surfaces. Oral Surg Oral Med Oral Pathol 1988; 66: 670-673.

35. Samaranayake LP, MacFarlane TW. The adhesion of the yeast Candida albicans to epithelial cells of human origin in vitro. Arch Oral Biol 1981; 26: 815-820.

36. Samaranayake LP, Hamilton D, MacFarlane TW. The effect of indigenous bacterial populations on buccal epithelial cells on subsequent microbial adhesion in vitro. Oral Microbiol Immunol 1994; (in press).
37. McCourtie J, Douglas LJ. Relationship between cell surface composition, adherence, and virulence of Candida albicans. Infect Immun 1984; 45: 6-12.

38. McCourtie J, Douglas LJ. Extracellular polymer of Candida albicans. isolation, analysis and role in adhesion. $J$ Gen Microbiol 1985; 131 : 495-503.

39. Klotz SA, Drutz DJ, Zajic JE. Factors governing adherence of Candida species to plastic surfaces. Infect Immun 1985; 50: 97-101.

40. Minagi $S$, Miyake $Y$, Inagaki $K$, Tsuru $H$, Suginaka $H$. Hydrophobic interaction in Candida albicans and Candida tropicalis adherence to various denture base resin materials. Infect Immun 1985; 47: 11-14.

41. Miyake Y, Fujita Y, Minagi S, Suginaka H. Surface hydrophobicity and adherence of Candida to acrylic surfaces. Microbios 1986; 46: 7-14

42. Nikawa H, Sadamori S, Hamada T, Satou N, Okuda K. Nonspecific adherence of Candida species to surface-modified glass. J Med Vet Mycol 1989; 27: 269-271.

43. Hawser SP, Douglas LJ. Biofilm formation by Candida species on the surface of catheter materials in vitro. Infect Immun 1994; 62: 915-921.

44. Tobgi RS, Samaranayake LP, MacFarlane TW. Adhesion of Candida albicans to epithelial cells exposed to chlorhexidine gluconate. J Med Vet Mycol 1987; 25: 335-338.

45. Darwazeh AMG, Lamey PJ, Lewis MAO, Samaranayake LP. Systemic fluconazole therapy and in vitro adhesion of Candida albicans to human buccal epithelial cells. $J$ Oral Pathol Med 1991; 20: 17-19.

46. Kogan G, Pavliak V, Sandula J, Masler L. Novel structure of the cellular mannan of the pathogenic yeast Candida krusei. Carbohydr Res 1988; 184: 171-182.

47. Doi M, Homma M, Chindamporn A, Tanaka K. Estimation of chromosome number and size by pulsed-field gel electrophoresis (PFGE) in medically important Candida species. J Gen Microbiol 1992; 138: 2243-2251.

48. Barns SM, Lane DJ, Sogin ML, Bibeau C, Weisburg WG. Evolutionary relationships among pathogenic Candida species and relatives. J Bacteriol 1991: 173: 2250-2255.

49. Roder BL, Sonnenschein C, Hartzen SH. Failure of fluconazole therapy in Candida krusei fungemia. Euro J Clin Microbiol Infect Dis 1991; 10: 173.

50. Casasnovas RO, Caillot D, Solary E et al. Prophylactic fluconazole and Candida krusei infections. $N$ Engl $J$ Med 1992; 326: 891-892. 